\title{
Lecturas performativas en la epigrafía femenina hispana medieval: el ejemplo del monasterio de San Pelayo (Oviedo)
}

\author{
Sonia Madrid Medrano \\ Universidad Complutense de Madrid \\ smadrid@ucm.es
}

\begin{abstract}
Performative Readings in Medieval Hispanic Epigraphy about Women: The Case of the San Pelayo Cloister

(Oviedo)
\end{abstract}

Este trabajo está adscrito al Proyecto AVIPES-CM (Ref. H2org/HUM-5742) de la Comunidad de Madrid/Fondo Social Europeo y al Proyecto Cithara de la UCM (Ref. PR87/r9-22659). Quiero agradecer a las Dras. Isabel Velázquez y Raquel Alonso y al Dr. Eduardo Valls sus pertinentes sugerencias e inestimable ayuda, pues sin duda han contribuido a mejorar notablemente este trabajo. No obstante, cualquier error o desacierto es culpa de la autora.

ReCIBIDO: 16-07-2020

EVALUADO Y ACEPTADO: 2I-09-202I

Territorio, Sociedad y Poder, No I6, 202I [PP. 57-70] 
Resumen: El espacio religioso femenino durante la Edad Media - el convento- presenta una singular complejidad, ya que permitía a las mujeres una libertad sin precedentes, aun cuando dependían, en gran medida, de la autoridad del varón. Trabajando en este escenario, el presente artículo ofrece, a través del conjunto de inscripciones del monasterio de San Pelayo de Oviedo, un análisis crítico de la percepción de lo femenino en este tipo de conventos a través de

Aвstract: The religious space for women in the Middle Ages - the convent- shows a peculiar complexity. It allowed women unprecedented levels of freedom even as they lived under masculine supervision. In this context, the present article offers a thorough critical analysis of the inscriptions gathered at the San Pelayo Monastery in Oviedo, regarding the perception of womanhood through la teoría de la performatividad. El análisis se centrará en inscripciones funerarias, a través de las cuales puede entreverse la difícil negociación de la identidad femenina cuando la mujer se dedica a tareas de sesgo tradicionalmente masculino.

Palabras ClaVe: Epigrafía funeraria; monasterio de San Pelayo; mujeres; abadesas; teoría de la performatividad.

the theory of performativity. The analysis zeroes in on funeral engravings, which bespeak the difficult negotiation of the feminine identity when women were performing tasks that were traditionally considered as masculine.

KeYwords: Funeral engravings; San Pelayo Monastery; women; abbesses; performative theory. 


\section{INTRODUCCIÓN: PANORÁMICA GENERAL}

Se ha escrito mucho sobre el papel de la mujer en la Edad Media y en verdad la posición de esta en la jerarquía eclesiástica no ha dejado de suscitar especial interés.

Durante los siglos medievales, entre el viI y el xv por poner los límites convencionales, la sociedad europea estuvo condicionada espiritual y en parte culturalmente por la Iglesia y la religión católica (Díaz de Rábago, 1999: 107).

Según la historiografía tradicional, durante la Edad Media, las mujeres podían vivir su religiosidad de diversos modos (Díaz de Rábago, I999: II7-I26; Muñoz Fernández, 20I7: 44-64). Tal y como afirma Díaz de Rábago había "tres tipos básicos de religiosidad femenina: las mujeres de Iglesia, las religiosas no regulares, herejes o no, y las mujeres que realizaban prácticas religiosas paganas» (1999: II7). Las religiosas regulares vivían en un espacio finito y determinado: el convento. Este, a su vez, presentaba una singular complejidad, ya que dotaba a las mujeres de una libertad sin precedentes (constituía una alternativa seria y cabal al matrimonio), pero también se convertía en el lugar de mayor control de la voluntad femenina, en tanto que las religiosas vivían, en numerosas ocasiones, subordinadas a la supervisión masculina. Las diferencias entre órdenes religiosas (benedictina, cisterciense, franciscana, clarisa, etc.) ya entonces determinaban el estilo de vida que habrían de llevar las mujeres, aunque lo más habitual era que la participación femenina en la Iglesia se realizara a través del ingreso en un monacato donde el sujeto femenino debía comprometerse a una clausura estricta. Las mujeres que conformaban el convento eran solteras en su mayoría, aunque también podían ingresar las viudas e, incluso, alguna casada - hay pocos casos, es cierto, pero existen: por ejemplo, el de Elvira Rodríguez y Rodrigo Peláez, que disolvieron su matrimonio en 1258 para iniciar sus respectivas vidas religiosas (Martín, 1982: 135)—. Las viudas, a decir verdad, resultaban capitales para el sustento económico del convento ya que poseían cierta riqueza — heredada de sus difuntos maridos- y podían ayudar a sostener la comunidad religiosa.

La vida contemplativa y de retiro a la que las mujeres se veían obligadas nace ya en los comienzos del cristianismo. Esto es, la discriminación de las mujeres en la Iglesia se remonta a la Biblia, y ya los Padres de la Iglesia recurrían a ella para justificar los fundamentos de la discriminación (vigilancia, tutela y aprobación). Valgan como ejemplo estas citas atribuidas a Pablo y 
utilizadas por Tertuliano u Orígenes, entre muchos otros (Torres, 20I7: 22):

Que las mujeres guarden silencio en las reuniones; no les está, pues, permitido hablar, sino que deben mostrarse recatadas (sumisas) como manda la ley. Y si quieren aprender algo, que pregunten en casa a sus maridos, pues no es decoroso que la mujer hable en la asamblea. (I Cor., I4, 34-35).

Que la mujer aprenda sin protestar y con gran respeto. No consiento que la mujer enseñe ni domine al marido, sino que debe comportarse con discreción. Pues primero fue formado Adán y después Eva. Y no fue Adán el que se dejó engañar, sino la mujer que, seducida, incurrió en transgresión. Se salvará, sin embargo, por su condición de madre, siempre que persevere con discreción en la fe, el amor y la santidad. (I Tim., 2, 8-I5. Pseudo-paulina).

Tal y como señaló Herbert Grundmann (I974: 7), los términos religio y vita religiosa se interpretaron como orden monástica y vida monástica. La vida religiosa dedicada plenamente al servicio de Dios (fundada en el concepto de ordines) solo podía concebirse como parte de los rígidos ordenamientos, cuya regla y disciplina protegían la existencia, así como la conducta de la persona religiosa contra cualquier recaída y degeneración. Todo movimiento religioso que no se integrara en estos ordines podía percibirse como un desafío a la Iglesia, y acabar, consecuentemente, convirtiéndose en secta o falsa religión (más aún si en el origen de estos movimientos se hallaban mujeres). Ahora bien, a partir del siglo XII (y sobre todo durante el siglo XIII) se produjo «una compleja fenomenología religiosa protagonizada por mujeres, estrechamente imbricada en la trama de las corrientes de renovación religiosa» (Muñoz Fernández, 20I7: 43). Así las cosas, otro tipo de órdenes, fuera de la clausura, comenzaron a gozar de más éxito entre las futuras monjas, ya que estas permitían mayor y mejor contacto con el mundo exterior —me refiero, por ejemplo a las órdenes mendicantes o, incluso, a la de Santiago- (Tenenbaum, 2004-2005).

No obstante, la generalización ofrecida por la crítica durante buena parte del siglo xx (sometimiento absoluto de la mujer al mandato masculino) ha quedado algo desfasada ante la aparición de nuevas aportaciones que, sin duda, han contribuido enormemente a situar a las mujeres medievales en una posición más poderosa de lo que se había creído hasta ahora. Por ejemplo, la península ibérica constituye una excepcionalidad en este sentido, pues la «importancia que la representación seńorial alcanzó en los monasterios femeninos [...] debe [...] explicarse en relación a la independencia que las damas castellanas conservaron en una Europa en la que las mujeres eran cada vez menos poderosas» (Alonso Álvarez, 2007: 702). Tal y como informa Raquel Alonso, esta singularidad no se había atendido en los años centrales de la Edad Media castellanoleonesa, aunque sí algo más en época altomedieval (Alonso Álvarez, 2007: 702).

En el caso de la nobleza, muy particularmente, las mujeres castellanas ejercieron un sólido patronazgo en la conformación de monasterios ${ }^{1}$ —en el caso que nos ocupa, el monasterio de San Pelayo de Oviedo, este estuvo muy vinculado con el infantazgo (Cayrol Bernardo, 20I4: 8) ya desde su fundación-.

\section{ESTUDIOS SOBRE LA MUJER EN LA EDAD MEDIA}

Los estudios de género, al igual que otras muchas disciplinas - economía, literatura, derecho, etc.— se han preocupado por analizar la situación de la mujer durante la Edad Media. En España, sobre todo desde la década de los 90, se ha conformado un gran corpus bibliográfico sobre esta cuestión ${ }^{2}$. Sin embargo, parece que aún hay un espacio que se ha tratado de manera marginal en este ámbito, a saber, la epigrafía. Los estudios sobre monacato femenino — en Espańa, principalmente — tienden

\footnotetext{
${ }^{1}$ Las infantas y las dominae ejercieron, en muchas ocasiones, mucha más influencia y poder que la propia monarquía (Cayrol Bernardo, 20I4).

${ }^{2}$ Destacan en los últimos años los títulos Mujeres en silencio: el monacato femenino en la España medieval (García de Cortázar y Teja (coords.), 2017) y Mujeres religiosas: beatas y beguinas en la Edad Media. Textos satíricos y misóginos (Santonja, 2007), además de numerosísimos artículos como los citados a lo largo de estas páginas.
} 
a presentar un panorama general sobre la mujer y su situación en su contexto histórico. Se han analizado órdenes, estamentos sociales, reflejos literarios, así como la influencia —o la ausencia de ella — que podían ejercer las mujeres en la vida pública y privada durante la Edad Media. A menudo, se ha hecho uso de las inscripciones de conventos e iglesias (sobre todo para el análisis de los espacios). Ahora bien, el texto epigráfico y su propia intencionalidad (de inmanencia en el tiempo, de ejemplo para generaciones futuras, de alabanza, etc.) no ha gozado de un análisis crítico desde el marco de los estudios feministas contemporáneos (algo que sí se hace, constantemente, con la literatura, ya esté escrita por mujeres u hombres). Por el contrario, es más frecuente encontrarnos con trabajos que describen el misógino mundo medieval a través de la vida conventual de las mujeres, aunque ya, por suerte, existen varios trabajos historiográficos que ponen en entredicho ${ }^{3}$ el status quo canónico. Los textos epigráficos, en este sentido, pueden servir como testimonio o constatación no solo de que un determinado monasterio fue fundado y llevado por mujeres, sino incluso, hasta cierto punto, de cómo dicho monasterio fue administrado por tales mujeres.

\section{METODOLOGÍA: LECTURA DE INSCRIPCIONES A}

TRAVÉS DE LA TEORÍA DE LA PERFORMATIVIDAD

El presente trabajo propone la lectura de textos epigráficos descriptivos de mujeres religiosas a través de una perspectiva performativa. La performatividad acaso es, hoy por hoy, la herramienta de análisis más utilizada en los estudios de género. Por tanto, la intención última de este artículo es dotar al texto epigráfico de protagonismo ya no solo histórico, sino también lingüístico en el marco de los estudios de género.

El filósofo del lenguaje J. L. Austin (2019) definió el enunciado pragmático como performativo o «realizativo», atribuyendo a la palabra la condición de «acto». Propuso así, por primera vez, el concepto de perfor-

\footnotetext{
3 Veánse, por ejemplo, los trabajos de García Calles, I972; Viñayo González, I982; Henriet, 2000; Martin, 2006; Alonso Álvarez, 2007 o Cayrol Bernardo, 2013 y 20I4, entre otros.
}

matividad, que establecía una obligada conexión entre acción y lenguaje como producto sincrético, es decir, simultáneo, trascendente de la dicotomía estructural moderna. Para Austin, ocurren tres tipos de actos al hablar: el locutivo (el hecho de decir algo, las palabras que se usan), el ilocutivo (la fuerza o intención detrás de las palabras); y el perlocutivo (la consecuencia, el efecto en el oyente o lector). La performatividad, naturalmente, es la articulación del acto ilocutivo (lo que se hace con las palabras). En este contexto performativo (o «realizativo»), no solo se usa la palabra, sino que esta implica forzosamente, a la par, una acción. En 1990, la filósofa y feminista Judith Butler integró esta teoría pragmática para desarrollar su «teoría performativa de género». En su libro Cuerpos que importan: sobre los limites materiales $y$ discursivos del "sexo», Butler parte de la filosofía del lenguaje para definir su teoría como «el reiterativo poder del discurso para producir los fenómenos que regula e impone» (2002: 19). El género, en este contexto y siempre según Butler, se construye mediante actos realizativos, es decir, a través del sentido factual o ilocutivo del discurso.

El método hermenéutico con el que se quiere aquí interpretar el corpus de inscripciones sobre abadesas ${ }^{4}$ aplica la teoría de la performatividad en los términos arriba esbozados: la inscripción como tal constituye un enunciado locutivo, esto es, expresa un significado y un sentido puramente semántico; pero, al mismo tiempo, genera un acto ilocutivo, es decir, realiza un sentido pragmático que va implicado en el enunciado, este es, en el contexto que tratamos, el género, la idea de femineidad. Dicho de otro modo, lo que tenemos en cada inscripción no solo es una caracterización singularizada de la personalidad de las monjas (valor locutivo de la inscripción), sino también una reconstrucción del género femenino en acto (no oposición a la definición teórica, esencialista o escolástica). Para entender cómo se reconstruye el género tenemos que atender a dos niveles de significado que la propia estructura pragmática sugiere: El primer nivel de significado debe preguntar cuál es el valor ilocutivo de la inscripción, o sea, cómo se cons-

\footnotetext{
${ }^{4}$ Aunque, como se verá en líneas posteriores, no todas las mujeres enterradas en este monasterio fueron abadesas o ni siquiera monjas, sino nobles benefactoras de la congregación.
} 
truye la femineidad que implica la inscripción. Para generar esta información, se articula una oposición deconstructiva muy básica, a saber, las nociones de actividad y pasividad como marcas fundamentales del género en tanto la construcción discursiva del género tiende a asociar «razón y mente» con

[...] masculinidad y capacidad de acción, mientras que el cuerpo y la naturaleza se asocian con la facticidad muda de lo femenino que espera la significación proporcionada por un sujeto masculino opuesto (Butler, 2007: I05)

La asociación, por tanto, de un grado de acción atribuida a un personaje femenino necesariamente desestabilizará la supuesta noción esencialista del sentido locutivo del enunciado, deconstruyendo de facto el sentido tradicional de género. Cuando sea este el caso, es decir, cuando se presente un enunciado que implica «lo femenino» habrá que pasar al segundo nivel de significado, a saber, deberá analizarse si la capacidad de acción, o el elemento «agente», como se prefiera, implica una desestabilización de lo masculino y lo femenino como atributos locutivos, y pasan estos, en consecuencia, a describir una relación dinámica de poder entre sujetos y objetos. Es decir, conviene estudiar si ese elemento agente precisamente se pondera frente a la mujer sumisa o vista como espejo, como icono moral (objeto definido por lo masculino), aseverando de facto un tipo de mujer «agente» distinto del modelo precedente.

\section{I. INSCRIPCIONES PARA EL CORPUS: EL monasterio de San Pelayo de Oviedo}

Para desarrollar las lecturas de las inscripciones a través de la metodología realizativa que acabo de exponer, he seleccionado los diferentes epitafios que se encuentran en el Monasterio de San Pelayo de Oviedo5. La elección de este monasterio no es baladí puesto que ha gozado

\footnotetext{
5 Para la historia detallada de los orígenes y vicisitudes de este monasterio durante la Edad Media, véase Fernández Conde y Torrente Fernández, 2007.
}

de singular importancia desde su fundación: sus orígenes se remontan, según la leyenda, a la Asturias del rey Alonso II el Casto; sin embargo «surge y se consolida tras un largo proceso en el que tendrán un activo papel mujeres de la aristocracia asturleonesa, incluidas algunas de las familias reinantes entre los siglos x y XII» (Fernández Conde y Torrente Fernández, 2007: I82). Entre ellas, la primera mujer que destaca es Teresa Ansúrez, esposa de Sancho I y madre de Ramiro III. Por razones políticas, la reina llevó los restos del mártir Pelayo a Oviedo y, al integrarse en la vida monacal de la ciudad, inició una serie de «relevos» de la custodia del cuerpo hasta la consolidación del monasterio (Fernández Conde y Torrente Fernández, 2007: I82).

No obstante, la consolidación del monasterio como centro de vital importancia — que perdura hasta nuestros días - se produjo cuando este adoptó la Regula Benedicti ${ }^{6}$ en el siglo xIII: la regla benedictina fue «decisiva [...] para la articulación y el buen funcionamiento de una entidad monástica en el pleno Medioevo [...], cuando la conformación monástica y la consolidación del señorío estaban en pleno desarrollo» (Fernández Conde y Torrente Fernández, 2007: 184). El monasterio se consolidó a la vez que el de San Vicente (masculino) y que la sede episcopal de San Salvador, hecho que pone de manifiesto la importancia de este monasterio femenino.

El gobierno de Aldonza Fernándiz, sobre todo, apuntaló el monasterio como un centro de poder y «fortaleza institucional» (Fernández Conde y Torrente Fernández, 2007: 20I) gracias a que "gozó del favor de la familia imperial, tanto del propio Alfonso VII como de su hermana doña Sancha» (Fernández Conde y Torrente Fernández, 2007: 20I). Así,

En cuanto a los aspectos social y económico, con la inestimable ayuda de la familia imperial y el concurso de la nobleza de su entorno, San Pelayo adquirirá las sólidas bases de su dominio territorial y jurisdiccional y, como señorío

\footnotetext{
${ }^{6}$ Eso sí, junto a la regla de su hermana Santa Escolástica para justificar así «la militancia por parte de mujeres en una regla escrita para varones» (Fernández Conde y Torrente Fernández, 2007: 202).
} 
monástico, se integrará en el tejido feudal de la sociedad de la época (Fernández Conde y Torrente Fernández, 2007: 202).

En definitiva, es razonable considerar que la notoriedad de este monasterio en la vida monacal femenina de la Edad Media lo convierte en un espacio paradigmático para estudiar las inscripciones que en él se hallan, pues no en vano la mayoría están realizadas por mujeres $y$ dedicadas a mujeres.

\subsection{ANÁLISIS DE LAS INSCRIPCIONES}

En el monasterio de San Pelayo han aparecido un total de trece inscripciones dedicadas a mujeres. Algunas resultan ser textos informativos, cuyo valor ilocutivo apenas sí consiste en reafirmar la naturaleza genérica de lo femenino como madre, hija o esposa, como es el primer caso (nótese, por cierto, cómo la definición de estas identidades es, naturalmente, relacional, por tanto, dependiente de otros sujetos):

I) Esta primera inscripción constituye una excepción en el conjunto epigráfico del monasterio, ya que doña Teresa no fue abadesa — ni siquiera monja, sino la viuda del rey Sancho I el Gordo y llegó al monasterio porque su hermana Sancha ya vivía allí (Cayrol Bernardo, 2013: 57)—. Según Suárez Botas (1984: 62), esta mujer era Teresa Pelliz, un personaje que «aparece documentado en el archivo de San Pelayo (fondo documental de San Bartolomé de la Nava, legajo D, núm. I4I" (Diego Santos, I995: I29). El epitafio, escrito en castellano, comprende unas medidas de 0,63 x o,8I y estaba cubierto con pequeños escudos con las armas de la casa de nava (Miguel Vigil, I887: I32), hoy deshechos.

\section{Aq(u)i iazdo(m)na T(eres) a filla de don P(er)o Dias de Nava et de do(m)na M(aria) F(e)rr(ande)s mu ller de P(er)o Bernaldo de Q(u)iros et madre de P(e)ro Ber[na]ldo e finó era M[C]CCLa IV mense Marcii ${ }^{7}$}

\footnotetext{
${ }^{7}$ Ref. AEHTAM 2544; IMA II6
}

Si la información carece de elementos relacionales, el enunciado se limita a marcar el género determinado por la estructura semántica, como en los casos 2, 3 y 4 (este último con atribución del género puramente gramatical).

2) Esta inscripción, dedicada a la abadesa Inés Suárez ${ }^{8}$, está escrita en prosa y utiliza una formulación atípica en epigrafía (domina Agnes), lo cual indica que es de composición tardía. Además, se equivoca en el año de su muerte, pues omite $X$ triplicat, texto que sí aparece en la otra inscripción dedicada a Inés. (Diego Santos, I995: I2I).

\section{Era MCC [XXX]VIII obiit abbadesa domina Agnes Sancti Pelagii}

Traducción: En la era de mil doscientos treinta y ocho (I200 d. C.) murió la abadesa doña Inés de San Pelayo ${ }^{10}$.

3) Esta inscripción tiene como protagonista a la abadesa María (la misma María que la que aparee en la última inscripción analizada) y es la última inscripción de todas las situadas en el claustrillo. Según Diego Santos (I995: 124), la fecha de la muerte de esta abadesa está equivocada en relación con el otro epitafio, pues en I2O2 «regía el monasterio dońa Urraca Suárez [...]. Si esta segunda lápida es copia de la primera, tuvo que interpretar por $X L$ las dos últimas letras $C I »$ (Diego Santos, 1995: 124).

\section{Era MCCXL obiit abbati(s)sa Sancti Pelagii \\ Domina Maria, requiescat in pace. Amen. ${ }^{11}$.}

Traducción: En la era de mil doscientos cuarenta (I202 d. C.) murió María, abadesa de San Pelayo, que descanse en paz. Amén.

\footnotetext{
${ }^{8}$ Inés Suárez es la misma abadesa que aparece en la duodécima inscripción analizada en este trabajo.

${ }^{9}$ Ref. AEHTAM 2442; IMA Io7b

${ }^{10}$ Todas las traducciones de los textos son mías.

${ }^{11}$ Ref. AEHTAM 2467; IMA iIIb
} 
4) Esta inscripción no se encuentra en el corpus del IMA. Se trata de una pieza reaprovechada en la que aún se aprecian una cruz de brazos iguales que se ensanchan en su remate, y el alfa y el omega.

$$
A\left(\text { cruz) } \Omega^{12}\right.
$$

Otras inscripciones, sin embargo, funcionan mucho mejor en sentido pragmático, de suerte que denotan, con más o menos dificultad, la interacción entre niveles de significado que se ha explicado en la metodología.

5) El epitafio de Cristina se localiza en la pared derecha del claustrillo, fijado al muro, al lado de la escalera que sube a la torre, aunque previamente estuvo en el suelo del segundo paño de dicho claustrillo. Realizada en hexámetros dactílicos, las medidas de la inscripción son $0,43 \times 0,55$, con letras de $2 \mathrm{~cm}$.

(Cruz) IntumuloXPOXri(sti)naiace(n)splacetisto, utile multarum speculum fuit $h($ a) ec viduaru $(m)$, co(m)place(n)s humilis, devota, pudica, fidelis. Thesauros studuit misera(n)do reponere c(o)elis, $q(u)$ os ubi subsidiis $p(r)$ op(r)iis annosa replevit, (a)ecclesi(a)e XPI Xri(sti)na ministra quievit. Era duce(nte)na millenaq(ue) q(u)i(n)taq(ue) dena MCCXV's.

Traducción: Cristina, que yace en este sepulcro, es grata a Cristo. Ella fue espejo a seguir de muchas viudas, complaciente, humilde, devota, honesta y fiel. Como era compasiva, trató de acumular tesoros para el cielo y, cuando con su aportación personal los colmó, ya cargada de años, descansó Cristina, la sierva de la iglesia de Cristo, en la era de mil doscientos quince (II77 d. C.).

Este ejemplo representa un caso claro de pasividad o «facticidad muda» (Butler, 2007: I05) atribuida al género femenino: el género se transparenta en la comprensión del sujeto como objeto que, a su vez, se en-

\footnotetext{
${ }^{12}$ Ref. AEHTAM $4 \mathrm{I} 44$

13 Ref. AETHAM 2460; IMA IIo.
}

tiende como espejo en el que mirarse - este arquetipo femenino pasivo ya lo encontramos en la Biblia, como he señalado en la introducción-. Cristina representa aquí a la mujer como vínculo pasivo con lo divino (placet isto), es decir, al mismo tiempo como baluarte moral y, en consecuencia, conducto material (icono) por el cual la divinidad se manifiesta. En este sentido, lo femenino parece concebirse como una identidad carente de agencia y sometida al valor moral que se le atribuye de facto. En este sentido, lo femenino adquiere el significado controlado y definido desde lo masculino (Butler, 2007: 105) por tanto termina fijando la noción del género como objeto moral impasible y paciente. Nótese por último cómo la única expresión de agencia (Thesauros studuit miserando reponere coelis) implica una noción pasiva (reponere) que se refuerza en la falta de control implícita en la definición que más tarde cierra la inscripción: aecclesiae XPI Xristina ministra.

Lo mismo ocurre en el caso del epitafio de infanta Teresa:

6) Este epitafio se encuentra hoy desaparecido quizá se perdió durante la reforma del monasterio que se llevó a cabo en el siglo XviII- La infanta Teresa fue hija de Bermudo II, rey de León. Alfonso de Carvallo (I695: 290) afirmó que Teresa fue abadesa y fijó su mandato entre los años IO22 y IO39. Sin embargo, no hay datos que puedan confirmar esa hipótesis, pues la infanta firmaba simplemente como Tarasia Christi ancilla Veremundi filia confirmat (Diego Santos, 1995: I22).

El epitafio presenta muchas variantes textuales, hecho que muestra el desacuerdo de diferentes autores (Alfonso de Carvallo, I695: 290; Quadrado, I855, I45; Miguel Vigil, I887: 133; Tirso, 1956: 197$)^{14}$ en la distribución de los renglones. No ayuda, tampoco, la mezcla de prosa y verso que presenta el texto ${ }^{15}$. No

\footnotetext{
${ }^{14}$ Las variantes textuales que presenta el texto son las siguientes: lín. I: hanc quam cernis, TIRSO; cava, CARVALLO, cavea, los demás. Lín. 3: Theresia, Carvallo. Lín. 4: genere orta, CARVALLO; generis orta, QUADRADO; parentatum, TIRSO; parentatu, QUADRADO; creemos preferible parentum (IMA) Lín. 6: imitare, TIRSO, QUADRADO y VIGIL; imitari, CARVALLO. Lín. 8: Martii, TIRSO y CARVALLOS; Magii, QUADRADO y VIGIL. (IMA IIo).

${ }^{15}$ Varios de los versos de este epitafio están tomados de poemas de Eugenio de Toledo. Para más información,véase Farmhouse Alberto, 20I0: 104-I05).
} 
obstante, el texto publicado por el IMA nos permite analizar el texto según los preceptos de la teoría de la performatividad: Teresa vuelve a constituir un vínculo pasivo con Dios (Christo dicata) que además se somete a la Regla (ut continet normam).

En quem cernis cava saxa tegit

compago sacra, hic dilecta Deo recubans

Tarasia Christo dicata, proles Veremundi regis

et Geloirae reginae, genere clara paren $(\mathrm{ta}) \mathrm{tu}(\mathrm{m})$,

clarior et merito vitam duxit praeclaram,

ut continet norma; hanc imitari velis

si bonus esse cupis

vel si obiit sub die (septimo) VII Klas. Magii, feria III

hora mediae noctis, era MLXXVII, post

peracta aetate saeculi porrecta per ordinem VI.

$\mathrm{Da}$, Christe, quaeso veniam, parce precor. Amen ${ }^{16}$

Traducción: he aquí a la que ves que oculta la sagrada construcción de esta hueca piedra. Aquí yace Teresa, amada de Dios, consagrada a Cristo, hija del rey Bermudo y de la reina Elvira. Ilustre por la estirpe de sus padres, más esclarecida por sus méritos, llevó una vida ejemplar como manda la Regla. Trata de imitarla, si quieres ser bueno. Murió el séptimo día antes de las Kalendas de mayo (25 de abril), un miércoles a media noche, en la era de mil setenta y siete (I039 d. C.), en la sexta edad del mundo. Dale el perdón, Cristo, te ruego que la perdones. Amén.

Igualmente ocurre en el caso de dos abadesas de nombre Aldonza (fallecidas en II74 y I323 respectivamente), cuyos atributos, como en el caso de Teresa y Cristina, devienen de su condición como objeto a través del cual se materializa la virtud.

7) El epitafio de la abadesa Aldonza, escrito en hexámetros dactílicos, se encuentra actualmente en el presbítero de la iglesia de las Pelayas. Sus medidas son de $0,34 \mathrm{~m} \times 0,55 \mathrm{~m} \mathrm{y}$, aunque ha sido objeto de numerosas

\footnotetext{
${ }^{16}$ Ref. AEHTAM 2454; IMA Io9.
}

variantes textuales, puede leerse desde una perspectiva performativa, ya que estas afectan a los años o a palabras de igual significado que deben suponerse para que encajen en el metro $(a b b a=a b b a t i s s a)$.
Inclita Fernandi p(ro)les comitis venera(n)di abba(tissa) sacris meritis Aldoncia felix hi(c) iacet ornata vi(r)tutu(m), laude beata mat(er) honestatis magn(a)e speculu $(m)$ pietatis t(er) septe(m) domui sex [por ses(qui)] a (n)nnis p(rae) fuit isti.
$\mathrm{Se}(\mathrm{m}) \mathrm{p}(\mathrm{er})$ in (a)eterna req(u)iescat pac[e p(rae)ca] mur.
Era du[ce(n)t]ena p(lus) millena duodena ${ }^{17}$.

Traducción: La ínclita hija del venerable conde Fernando, Aldonza, feliz abadesa por méritos propios, yace aquí. Adornada de virtudes, colmada de alabanzas, madre de gran honestidad, espejo de piedad, gobernó esta casa veintidós ańos y medio. Pidamos que descanse siempre en paz. En la era mil doscientos doce (II74 d. de C.).

8) Esta lápida se sitúa en el tercer paño del claustrillo y está también escrita en hexámetros. Las medidas son de $0,57 \mathrm{~m}$ x 0,62m, con unas letras de $4,5 \mathrm{~cm}$.

Xpr dilect(r)is Eliso[ncia] provida, rect(r)ix hic est deposita g[en]erosa, modesta, p(er)ita, su(p)[plex, munifica et cl]austri custos et am[ica], et miseris m[iserens l]auda(n)dis morib(us) h[e] $\mathrm{re}[\mathrm{s}]$

Tunc [a(n)nos mille t(ri)plex $C$ dies simul ille bisq(ue) decem g[essit I duplex c(um)] sedula cessit $^{18}$.

Traducción: Aquí está enterrada la amante de Cristo, Aldonza, providente directora, generosa, modesta, culta, humilde, munificiente,

\footnotetext{
${ }^{17}$ Ref. AEHTAM 2536; IMA II4

${ }^{18}$ Ref. AEHTAM 2496; IMA II2.
} 
guardiana y amiga del claustro, compasiva con los pobres, heredera de una moral loable. Aquel día se cumplían los mil trescientos veintidós años cuando cesó sus ocupaciones (I322 d. C.).

El caso de Sancha Fernández es análogo a los de Cristina, Teresa y las dos Aldonzas. Los atributos de Doña Sancha Fernández descansan en una serie de «herencias» definidas desde lo masculino (estirpe y honra) que además necesitan de la intervención de terceros para poder validarse en el cielo (nótese cómo anima el epitafio a "pedir" por la recompensa cristiana de la abadesa).

9) Esta lápida de la abadesa Sancha es la segunda situada en la iglesia del monasterio. Mide $0,68 \mathrm{~m}$ x 0,56m y sus letras ocupan $4,5 \mathrm{~cm}$. Llama la atención la irregularidad métrica del texto: comienza con un dístico y continúa con dos hexámetros para, a continuación, terminar con dos pentámetros (Diego Santos, 1995: I29).

In fovea mortis gregis custodia fortis clauditur, est ideo co(m)memorata Deo, $h(a)$ ec merito moris $g(r a) d u(m) q(u a)$ esivit honoris,

si gen(us) ha(n)c d(e)corat satis illa(m) fama d(e) corat;

Sancia Ferna(n)di n(o)m(in)e dicta fuit. Ut sit luce sita corde p(re)cemur ita, q(ua)e obiitme(n)se Aug(us)ti era MCCCLXXV $V^{\text {t9 }}$.

Traducción: En este agujero de la muerte está enterrada la fuerte guardiana de la grey, es, por tanto, recordada ante Dios. Por su propio mérito, su honradez llegó a las gradas del honor. Si su estirpe la adorna, se honra igual por el clamor de la fama. La conocieron por el nombre de Sancha Fernández. Pidamos de corazón que sea llevada al Reino de la Luz. Murió en el mes de agosto, en la era de mil trescientos setenta y cinco (I337 d. C.).

\footnotetext{
${ }^{19}$ Ref. AEHTAM 2537; IMA II5
}

Ahora bien, no todas las inscripciones mantienen una equivalencia más o menos cabal entre el sentido locutivo y el sentido ilocutivo; muchas de las inscripciones trascienden el primer nivel y generan un conflicto por causa del cual se imputa cierto grado (y no menor) de agencia a la protagonista de la inscripción.

El caso contrario a los epitafios de Cristina, Teresa y Aldonza, acaso el ejemplo más claro de dislocación entre los atributos tradicionales de los géneros y el conflicto desestabilizador de estos (esto es, "el género en disputa» (Butler, 2007)) se da en el epitafio de otra Aldonza (fallecida en 1323). Como quiera que la organización administrativa del monasterio determinaba que los conventos debían estar bajo supervisión masculina (la capacidad de agencia se representa como parte del género masculino), llama la atención que las inscripciones que valoran la capacidad agente de facto deriven características masculinas (agencia, control) hacia una descripción de lo femenino. Es la cultura, debe advertirse, la que asigna el significado de los roles de género, no se olvide.

Io) La Aldonza de este epitafio es la misma que la de la octava inscripción comentada en estas páginas (es decir, la fallecida en I323). La lápida estuvo en la iglesia, pero hoy por hoy se encuentra en el Museo Arqueológico Provincial. Escrita en dísticos, salvo al comienzo, se trata de una pieza de grandes dimensiones $(0,96 \mathrm{~m} \mathrm{x}$ $0,54 \mathrm{~m}$ y un grueso $0,16 \mathrm{~m}$ ).

Fle(n)t abbatiss(a)e plangu(n)tq(ue) fun(us)
amaru(m)
isto submiss(a)e tumulo c(o)et(us) monacharu(m)
q(ua)s pr(a)evelavit, rexit docuitq(ue) creavit
has suade(n)do cita qu(a) eq(ue) seq(u) licita
nob(i)lib(us) genita fuit h(a)ec Eliso(n) cia vita
norma bonitatis me(n)te devota satis
ex(s)titit huic cura claust(r)i defe(n)d(er)e iura
sic ea dist(ri)buit cuilibet ut licuit
milleq(ue) ter ce(n)tu(m) q(ue) sesagi(n)ta (sic)
dat era
unu(m) pl(us) num(er)a tu(n)c hoc sub(i)it
monume(n)tu(m)
isto submiss(a)e tumulo c(o)et(us) monacharu(m) $q(u a)_{s}$ pr(a)evelavit, rexit docuitq(ue) creavit has suade(n) do cita qu(a)eq(ue) seq(u)i licita nob(i)lib(us) genita fuit h(a)ec Eliso(n) cia vita norma bonitatis me(n)te devota satis ex(s)titit huic cura claust(r)i defe(n)d(er)e iura sic ea dist(ri)buit cuilibet ut licuit milleq(ue) ter ce(n)tu(m) q(ue) sesagi(n)ta (sic) dat era unu(m) pl(us) num(er)a tu(n)c hoc sub(i)it 
Traducción: Llora y se lamenta por la amarga muerte de la abadesa, sepultada en este sepulcro, la comunidad de monjas, que ella custodió, dirigió, enseñó y formó, pronta en persuadirlas a seguir los dictados de la ley. Aldonza fue hija de nobles padres, en vida, con su norma de bondad, de gran devoción su mente. Fue su constante cuidado la defensa de los derechos del claustro, así ella dio a cada cual lo que se le permitía. La era andaba por el ańo mil trescientos sesenta y uno (I323 d. C.), cuando vino a este monumento.

Caracteriza a Aldonza una capacidad de acción muy valiosa para su «comunidad de monjas, que ella custodió, dirigió, enseñó y formó». La inscripción explicita de una parte la jerarquía de poder que encabeza la abadesa — sin intervención de ningún elemento masculino- - Y, de otra, la dinámica relacional que articula dicha jerarquía como estructura de poder. Los atributos de Aldonza son resultado de su propia agencia en el mundo: desde la dirección, la formación y la custodia de la comunidad (de la que se halla al cargo) hasta «la defensa de los derechos del claustro» $y$ el reparto de lo que «a cada cual lo que se le permitía». En ningún momento se construye el personaje en relación pasiva con un sujeto ajeno a ella misma (es decir, definiendo a Aldonza como objeto pasivo), de suerte que se construye así un personaje - y el género que se la asocia - por causa de su propia capacidad de acción y control. Si los atributos de Cristina o Teresa presuponían la femineidad tradicional como «lo pasivo», Aldonza necesariamente deconstruye el sentido clásico de lo femenino integrando en él las capacidades habituales que definen lo masculino (recuérdese, capacidad de acción, esto es, agencia, y control).

Las tres inscripciones dedicadas a la abadesa Inés Suárez destacan en un sentido parecido, aunque con más matices, que el de Aldonza (recuérdese, fallecida en 1323). En el caso concreto de Doña Inés Suárez, pasa a ser esta quien dicta la Regla (normam dictavit) e incluso es ella la que domina al rebaño (pavit utroque gregem) del convento.
II) El epitafio a doña Inés Suárez está en dísticos elegíacos y data del año i2oo. Aunque está muy deteriorado debido a la calidad de la piedra, sí se han podido tomar sus medidas que son: $0,47 \mathrm{~m} \mathrm{x}$ $0,52 / 0,57 \mathrm{~m}$.

Mors rapit Agnetem quis orbis gratios illi hanc premit, hanc relevat, hic nocet inde iuvat hanc virtus <aut> adducet doctrina magistram stirps <munit> dominam, copia fama parent abbatisa q(u)idem normam dictavit in actu protulit in verbo, pavit utroq(ue) gregem $C$ pl(us) mi(l)le duplat duo q(u)adruplat $X$ triplat era ${ }^{21}$.

Traducción: la muerte nos arrebató a Inés, ¿quién más grata que ella a la comunidad? Reprende a una, ensalza a otra, aquí castiga, allí ayuda. A ella la harían maestra su virtud o sabiduría; su estirpe le da firmeza de señora, le ayudan su fama y riquezas. Como abadesa dictó la Regla en cada caso y comunicó la orden. Con ambos recursos dominó su rebaño. En la era de I238.

En los casos que acabo de mostrar, este análisis se confirma también desde una perspectiva histórica: Cristina no fue abadesa - y tampoco hay suficientes datos para afirmar que Teresa lo fuera- e Inés sí.

Si se analizan las condiciones que propone Butler, hay una distinción entre la naturaleza genérica de Teresa e Inés. El valor ilocutivo de estas inscripciones construye el género, es decir, la descripción implica una versión de lo femenino, y ese es el valor ilocutivo en el contexto de género. La implicatura asevera dos tipos de mujer: de una parte, aquella que se construye como una identidad carente de agencia, esto es, pasiva (que es la forma especular: la mujer en la que te debes reflejar, el modelo moral, inalterado e inalterable) y, de otra, aquella con capacidad de agencia (en cuyo caso habría que analizar cómo es esa capacidad y cómo se

\footnotetext{
${ }^{21}$ Ref. AETHAM 2449; IMA Io8.
} 
pondera). Domina en este caso la noción femenina que entra en conflicto con la definición cultural no marcada, esto es, lo que hemos denominado en la metodología el segundo nivel de significado, por causa del cual se desestabiliza, mediante la aseveración de la capacidad de agencia, la definición esencialista de lo femenino. La capacidad de Inés para «Reprende[r] a una, ensalza[r] a otra, aquí castiga[r], allí ayuda[r]» impone un grado de acción y control que, por causa del acto ilocutivo (la implicatura factual), va en contra de la atribución clásica marcada por la idea esencialista del género (es el género masculino el que actúa, el que se yergue como sujeto activo sobre el objeto pasivo). En la mayoría de inscripciones, se trata de fusionar los dos tipos de género femenino; sin embargo, siempre hay un nivel que domina sobre el otro, en este caso, el nivel pragmático (segundo) que desestabiliza el sentido tradicional del género.

I2) Hay otro epitafio de dos hexámetros dedicado a Inés Suárez situado bajo el arcosolio. Está empotrado en el muro del claustrillo del monasterio a espaldas del monumento que contiene el epitafio referido anteriormente. Sus medidas son: $1,59 \mathrm{~m}$ x $0,60 \mathrm{~m}$; las letras miden $3,5 \mathrm{~cm}$.

(cruz con alfa y omega pendientes)

Re pro teste data mo[r]ti est Agnete vocata orbi crudelis sancti(s)si[m]a prodiga celis ${ }^{22}$.

Traducción: dando su obra testimonio a su favor, fue llamada por la muerte Inés, dura con su rebaño, gran santa y pródiga en el cielo.

Nuevamente aparece el conflicto que genera la lectura pragmática en combinación con el sentido tradicional (vale decir, esencialista) del género. En estos dos hexámetros, Inés se caracteriza por ser «dura con su rebaño» [orbi crudelis], aseverando así una jerarquía que presupone, a su vez, una es-

\footnotetext{
${ }^{22}$ Ref. AEHTAM 2436; IMA Iо7a.
}

tructura de poder en la que Inés se sitúa a la cabeza. La estructura de poder implica, por definición, una dinámica de agencia que articula necesariamente sus vínculos intrínsecos como sujeto (activo) y objeto (pasivo). Inés, nuevamente, vuelve a ocupar el lugar del sujeto agente, que se reserva en la tradición a lo masculino, generando así el conflicto del segundo nivel al que nos referimos. Se combinan aquí, pues, los dos niveles de significado; sin embargo, la agencia propia del género masculino (orbi crudelis) en el segundo nivel predomina sobre la pasividad asignada al género femenino (prodiga celis) ${ }^{23}$.

I3) El epitafio de la abadesa María está situado en la inmediación de la puerta del claustrillo y lo componen dísticos con rima al final. Sus medidas son: $0,395 \mathrm{~m} \mathrm{x}$ $0,465 \mathrm{~m}$; las letras son de $4 \mathrm{~cm}$.

\section{Ortu clara via mor(um)fuit ista Maria \\ Dux gregis, egr(e)gia fida, modesta, pia, $X P O$ devota, tactus a labe remota, e(ss)e stude(n)s tota c(r)iminis absq(ue) nota. Post $M$ finivit et cu(m) $C$ ter era subiit ${ }^{24}$.}

Traducción: Esta María, preclara de nacimiento, fue la rectitud de costumbres, guía del rebaño, egregia, fiel, modesta, piadosa, consagrada a Cristo y apartada de deshonra carnal, se esforzaba por mantenerse toda sin tilde de pecado. Murió en la era de mil trescientos uno (I263 d. C.).

\footnotetext{
${ }^{23}$ Cabe incluso aquí un análisis más profundo que presupone la noción de bien como constructo masculino. Si la capacidad de agencia (la capacidad de Inés para poner en práctica su gobierno) es la que le reporta su prodigalidad en el cielo, debe suponerse que el buen uso de los atributos masculinos es el que fundamenta la entrada de la mujer en el cielo e implica una concepción del bien como producto realizativo de lo masculino en la tierra. Como quiera que es una mujer en este caso quien lleva a cabo esa realización de lo masculino, debe ponerse entonces en cuestión (segundo nivel del análisis) la definición de ambos polos del género en relación con la moral cristiana. Nótese bien que no se pretende resolver la definición esencialista del género (ni en este ejemplo, ni en los demás que aquí se presentan) presentando definiciones alternativas, sino que más bien deseo llamar la atención sobre la inestabilidad de los roles de género que se implican el discurso textual de las inscripciones (que es, a la sazón, el fundamento de la teoría performativa de Butler).

${ }^{24}$ Ref. AEHTAM 2466; IMA IIIa.
} 
Este epitafio es el que aúna, del modo más transparente, los dos niveles de significado: la abadesa fue "guía o líder de su rebaño» (dux gregis), pero también «modesta, piadosa y devota y apartada de la deshonra carnal» (modesta, pia, Christo devota, tactus a labe remota). La capacidad de liderazgo, aunque más amable que la «dureza» de Inés, es evidente en cualquier caso y connota la misma estructura jerárquica, así como la misma dinámica de poder implícita en dicha jerarquía y que definía la caracterización genérica de Inés. Ahora bien, en este caso concreto, la capacidad de agencia se oblitera o, como poco, pierde relevancia frente a las condiciones de pasividad consustanciales al marco de referencia moral que explicita las capacidades (incluida la capacidad de liderazgo) de María. Los atributos de esta abadesa Christo devota, tactus a labe remota implican por lo general su condición de objeto subordinado a una volición ajena, la cual sirve para relocalizar la capacidad de acción de la abadesa fuera de su propia condición como sujeto. En estas condiciones, la presuposición de una capacidad agente y de control en la primera parte de su epitafio (predominio del conflicto realizativo, es decir, del segundo nivel) debe coexistir «en disputa» (Butler, 2007) con una reafirmación de la definición esencialista del género. Provoca esto la paradoja de que la deconstrucción pragmática de lo masculino en la primera parte del epitafio se niega en la segunda parte, reafirmando, para más dificultad definitoria, el conflicto fundamental genérico que transparenta la inscripción.

\section{Conclusiones}

La abadesa es un tipo femenino muy interesante desde el punto de vista de la agencia y el género: se trata de una mujer en cuya posición, necesariamente, debe ejercer acciones tradicionalmente masculinas. La acción y sus «virtudes», la eficiencia, la organización, etc. Estas cualidades, asignadas culturalmente a lo masculino, se cuelan en la construcción de lo femenino que implica la inscripción. A partir de aquí ya podemos ver que se construyen distintos tipos de feminidad: de una parte, la identidad que se acerca al polo activo y, de otra, la que se acerca al polo pasivo.

El análisis que aquí se ha presentado se basa en un fundamento lingüístico y no histórico. Se trata de un análisis pragmático, que permite entender cómo estas inscripciones crean diversos tipos de feminidad. El discernimiento de estos tipos permitiría ahondar, gracias al análisis lingüístico, en la forma de representación de los géneros en el ámbito de la epigrafía, que necesariamente, a su vez, debe poder completar los análisis históricos que hasta ahora se han llevado a cabo. 


\section{REFERENCIAS}

AEHTAM = BANCO DE DATOS DEL ARCHIVO EPIGRAFICO DE HISPANIA TARDOANTIGUA Y MEDIEVAL (2005) (HTTP://hesperia.ucm.es/consulta_aehtam/web_aehtam/index.html).

Alfonso de Carvallo, Luis (1695): Antigüedades y cosas memorables del Principado de Asturias, Madrid, Julián de Paredes Impresor de Libros.

Alonso Állvarez, Raquel (2007): «Los promotores de la orden del Císter en los reinos de Castilla y León: familias aristocráticas y damas nobles», Anuario de Estudios Medievales, 37/2, p. 653-710.

нттр://estudiosmedievales.revistas.csic.es/index.php/estudiosmedievales/ article/view/5o/5I

Austin, John L. (2019): Cómo hacer cosas con palabras, Buenos Aires - Barcelona - México, Paidós.

Avilés, Tirso de (1956) ARMAS Y LINAJES DE Asturias Y ANTIGÜEDADES DEL PRINCIPADo, Ms. De fines del siglo XVI (edición del Instituto De Estudios Asturianos).

Butler, Judith (2002): Cuerpos que importan: sobre los limites materiales y discursivos del «sexo», Buenos Aires - Barcelona - México, Paidós.

ButLER, Judith (2007): El género en disputa: el feminismo y la subversión de la identidad, Buenos Aires - Barcelona - México, Paidós.

Cayrol Bernardo, Laura (2013): «El monasterio de San Pelayo de Oviedo: infantado y memoria regia», Territorio, sociedad y poder, 8 , p. 53-66 (https://www.unioviedo.es/reunido/index.php/TSP/article/ view/10167/9826).

Cayrol Bernardo, Laura (2014): «De infantas, domnae y Deo votae. Algunas reflexiones en torno al infantado y sus señoras», SVMMA. Revista de cultures medievals, p. 5-23. (https://revistes.ub.edu/index.php/SVMMA/article/view/IO527).

Díaz de Rábago, Carmen (1999): «De vírgenes a demonios: las mujeres y la Iglesia durante la Edad Media", Dossiers feministes, 2, p. I07-I29. (http:// www.e-revistes.uji.es/index.php/dossiers/article/view/792/693).

Farmhouse Alberto, Paulo (20Io): «Epigrafía medieval y poesía visigótica: el caso de Eugenio de Toledo", Sylloge Epigraphica Barcinonensis (SEBArc), VIII, p. 97-IO8. (HTTP: https://raco.cat/index.php/SEBarc/ article/view/254609/341556).

Fernández Conde, Francisco Javier - Torrente Fernández, Isabel (2007): «Los orígenes del monasterio de San Pelayo (Oviedo): aristocracia, poder y monacato", Territorio, sociedady poder, I, p. I8I-202. (http://digibuo. uniovi.es/dspace/bitstream/I065I/28808/2/Origenes942I-I5496-I-SM.pdf).

García Calles, Luisa (1972): Doña Sancha, hermana del emperador, León, Universidad de León.

García de Cortázar, José Ángel - Teja, Ramón (COORds.) (2017): Mujeres en silencio: el monacato femenino en la España medieval, Aguilar de Campoo, Fundación Santa María la Real del Patrimonio Histórico.
Grundmann, Herbert (1974): Movimenti religiosi nel medieoevo. Richerche sui nessi Storici tra l'eresia, gli Ordini mendicanti e il movimiento religioso femminile nel XII e XIII secolo e sulle origini storiche della mistica tedesca, Bologna, Il Mulino.

Henriet, Patrick (2000): «Deo votas. L'Infantado et la fonction des infantes dans la Castille et le León des X-XII siècles», en Henriet, Patrick — Legras, Anne-Marie (eds.), Au cloître et das le monde. Femmes, hommes et sociétés (IX-XV siècles). Mélanges à l'honneur de Paulette L'Hermite-Leclercq, París, Presses de l'Université de Paris-Sorbonne, p. I89-199.

Diego Santos, Francisco (1995): Inscripciones medievales de Asturias, Principado de Asturias, Oviedo, Consejería de Educación, Cultura, Deportes y Juventud.

Martin, Therese (2006): Queen as King: Politics and Architectural Propaganda in Twelfth-Century Spain, Leiden-Boston, Brill.

Martín, José Luis (1982): Documentos del Archivo Catedralicio de Zamora: primera parte (II28-I26I), Salamanca, Ediciones Universidad de Salamanca.

Miguel VigiL, Ciriaco (I887): Asturias monumental, epigráfica y diplomática: datos para la historia de la provincia, Oviedo, Imprenta del Hospicio Provincial.

Muñoz FernándeZ, Ángela (2017): «Las expresiones femeninas del monacato y la devoción: reclusas, monjas, freiras y beatas», en García de Cortázar, José Ángel - Teja, Ramón (coords.), Mujeres en silencio: el monacato femenino en la España medieval, Aguilar de Campoo, Fundación Santa María la Real del Patrimonio Histórico, p. 4I-72.

Quadrado, José María (I855): Recuerdos y bellezas de España: Asturias y León, Madrid, Imprenta de Repullés.

Santonja, Pedro (2007): Mujeres religiosas: beatas y beguinas en la Edad Media. Textos satíricos y misóginos, Alicante, Universidad de Alicante.

Suárez Botas, Gracia (1984): La epigrafía medieval de Oviedo, como fuente histórica, Memoria de Licenciatura (inédita).

Tenenbaum, Felipe (2004-2005): «La mujer en el convento: Fructus Sanctorum", Memorabilia: Boletín de literatura sapiencial, 8

(нттр://parnaseo.uv.es/Memorabilia/memorabilia8/Felipe/index.htm).

ToRres, JuANa (2017): «Mujeres y altares: entre la Roma pagana y la Roma cristiana», en García de Cortázar, José Ángel - Teja, Ramón (coords.), Mujeres en silencio: el monacato femenino en la España medieval, Aguilar de Campoo, Fundación Santa María la Real del Patrimonio Histórico, p. II - 40.

Quadrado, José María (I855): Recuerdos y bellezas de España: Asturias y León, Madrid, Imprenta de Repullés.

ViñAyo GonZÁlez ,ANTONio (I982): «Reinas e Infantas de León, abadesas y monjas del monasterio de San Pelayo y de San Isidoro», en Semana de historia del monacato cántabro-astur-leonés, Oviedo, Monasterio de San Pelayo, p. I23-I35. 